\title{
Functionalization of 4-bromobenzo[c][2,7]naphthyridine via regioselective direct ring metalation. A novel approach to analogues of pyridoacridine alkaloids
}

\author{
Benedikt C. Melzer, Alois Plodek and Franz Bracher ${ }^{*}$
}

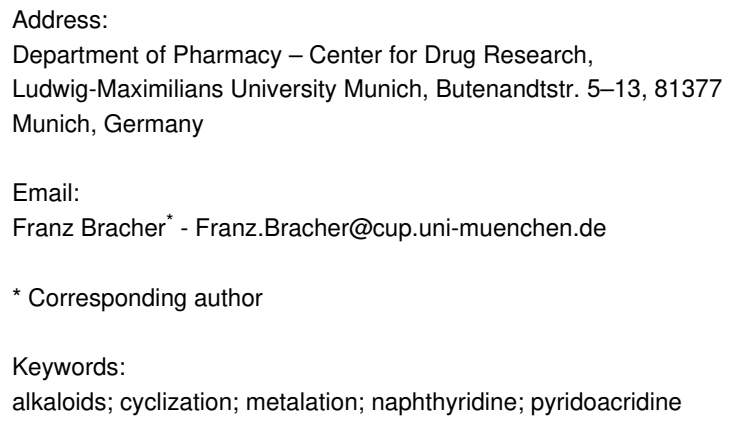

\author{
Beilstein J. Org. Chem. 2019, 15, 2304-2310. \\ doi:10.3762/bjoc. 15.222 \\ Received: 10 August 2019 \\ Accepted: 18 September 2019 \\ Published: 26 September 2019 \\ Associate Editor: I. Baxendale \\ (C) 2019 Melzer et al.; licensee Beilstein-Institut. \\ License and terms: see end of document.
}

\begin{abstract}
Readily available 4-bromobenzo[c][2,7]naphthyridine undergoes regioselective direct ring metalation at $\mathrm{C}-5 \mathrm{with} \mathrm{TMPMgCl} \cdot \mathrm{LiCl}$ at $-40{ }^{\circ} \mathrm{C}$. Quenching with various electrophiles gives a broad range of 5-substituted products, which are building blocks for the synthesis of heterocyclic natural products and analogues thereof. In combination with a Parham-type cyclization a novel approach to pyrido[4,3,2-mn] acridones has been worked out.
\end{abstract}

\section{Introduction}

Polycyclic aromatic alkaloids are a unique class of natural products with a broad pattern of biological activities. One of the most prominent classes are the so-called pyridoacridine alkaloids to be found in diverse marine sources (tunicates, sponges) Their chemistry, pharmacology and biosynthesis have been the subject of a couple of review articles [1-4]. Another source of polycyclic aromatic alkaloids are tropical plants, e.g., the Annonaceae family [5].

A very common structural feature of the abovementioned alkaloids is the benzo[c][2,7]naphthyridine ring system, as exemplified by the marine alkaloids amphimedine (1), ascididemin (2), kuanoniamine A (3), styelsamine D (4), and eilatin (5). Skyler and Heathcock described, based on the occurrence and proposed biosyntheses of known alkaloids, a "pyridoacridine family tree" which is claimed to be useful for designing total synthesis, but also for predicting yet undiscovered alkaloids from this chemotype [6]. Only two tricyclic benzo[c][2,7]naphthyridine alkaloids, perlolidine (6; from rye grass, Lolium perenne) [7] and subarine (7; from an unidentified marine tunicate) [8], have been identified yet (Figure 1).

Considerable work was published on the total syntheses of marine pyridoacridine alkaloids, and numerous different approaches for the construction of the tetra- to heptacyclic ring systems have been developed over about three decades 


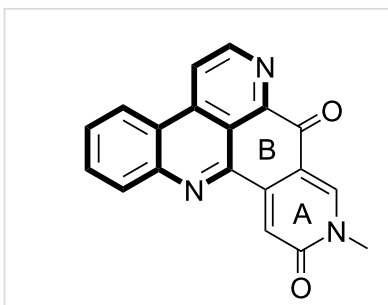

amphimedine (1)

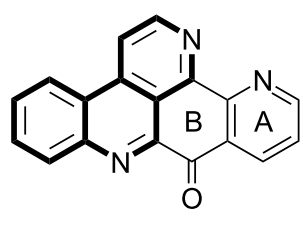

ascididemin (2)<smiles></smiles>

kuanoniamine A (3)<smiles>NCCc1cc(O)c2nccc3c2c1Nc1ccccc1-3</smiles>

styelsamine D (4)

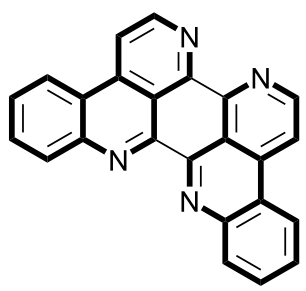

eilatin (5)<smiles>O=c1[nH]ccc2c(=O)[nH]ccc12</smiles>

perlolidine (6)<smiles>COC(=O)c1cccnc1-c1nccc2c1c(=O)[nH]c1ccccc12</smiles>

subarine (7)

Figure 1: Marine pyridoacridine alkaloids amphimedine (1), ascididemin (2), kuanoniamine A (3), styelsamine D (4) and eilatin (5), as well as the two known tricyclic benzo[c][2,7]naphthyridine alkaloids perlolidine (6) and subarine (7) with the common benzo[c][2,7]naphthyridine moiety highlighted in bold.

[1-4]. One promising approach consists of building up the common benzo[c][2,7]naphthyridine unit first, followed by appropriate functionalization at positions 4 and 5 . The pioneering work of Quéguiner in this field allowed the construction of 4-monosubstituted and 4,5-disubstituted benzo[c][2,7]naphthyridines utilizing ortho-directed ring metalation/biaryl cross-coupling strategies [9]. 4-Chlorobenzo[c][2,7]naphthyridine (9a) was conveniently converted into other 4-substituted benzo[c][2,7]naphthyridines by substitution reactions with nucleophiles (alcoholates, phenolates), acyl anions (generated by umpolung of aldehydes with imidazolium salts) and by palladium-catalyzed cross-coupling reactions (Suzuki, Stille) [10]. A related Stille cross coupling of a benzo[c] $[2,7]$ naphthyridine bearing a triflate group at C-5 gave an intermediate for the total synthesis of amphimedine (1) [11] 4-Chloro-5-methylbenzo[c][2,7]naphthyridine (8) was oxidized at the methyl group to give an aldehyde. Subsequent modifications of the formyl group and Stille couplings at C-4 gave a number of 4,5-disubstituted benzo[c][2,7]naphthyridines (Figure 2A) [12]. Organolithium compounds were added at C-5 of 4-chloro- (9a) and 4-fluorobenzo[c][2,7]naphthyridine (9b) as well as the 4-carboxamide 9c to give 5-substituted-5,6dihydro derivatives, which were readily aromatized with manganese dioxide [13]. Further functionalization was performed by Stille cross coupling of a 4-chloro intermediate [12]. Our group demonstrated that nucleophilic radicals (1,3,5-trioxanyl, ethoxycarbonyl, methyl [14], but not benzoyl [15]) generated with peroxide under Minisci conditions, readily add to C-5 of 4-bromo- (9d) and 4-acetylbenzo[c][2,7]naphthyridine (9e) to give 5-substituted-5,6-dihydro derivatives, which undergo rearomatization as described above (Figure 2B). 4-Bromo-5(methoxycarbonyl)benzo[c][2,7]naphthyridine generated this way gave, after Suzuki cross-coupling at C-4, intermediates for the synthesis of analogues of ascididemin (2) [16]. Introduction of (hetero)aromatic rings bearing ester groups in ortho-position into 4-bromobenzo[c][2,7]naphthyridine (9d) under Suzuki or Negishi conditions gave 4-aryl derivatives 10 which underwent cyclization to pyridoacridones through directed remote ring metalation at $\mathrm{C}-5$, followed by spontaneous intramolecular trapping of the ester group [17,18] (Figure 2C).

The successful directed remote metalation of 4-arylbenzo[c][2,7]naphthyridines $\mathbf{1 0}$ prompted us to investigate direct ring metalation of the readily available 4-bromo intermediate 9d [14]. Trapping of the envisaged 5-metalated intermediate with various electrophiles, followed by transformations of the 4-bromo residue (cross-coupling reactions, nucleophilic substitutions) should open the opportunity to generate a broad variety of 4,5-disubstituted benzo[c][2,7]naphthyridines as building blocks for natural products total synthesis (Figure 2D).

\section{Results and Discussion}

For the envisaged direct ring metalation of 4-bromobenzo[c][2,7]naphthyridine (9d) the choice of an appropriate base was essential. Alkyllithium bases were not suitable, since two undesired reactions were anticipated: As mentioned above, 4-substituted benzo[c][2,7]naphthyridines tend to add organolithium compounds to the C-5-nitrogen double bond [13] (see Figure 2B), further undesired bromo-lithium exchange is possible at C-4. Since halogen substituents at C-4 are further 
A)

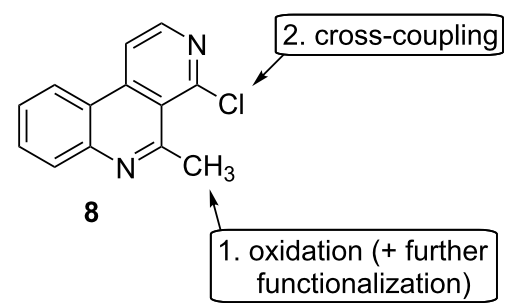

C)

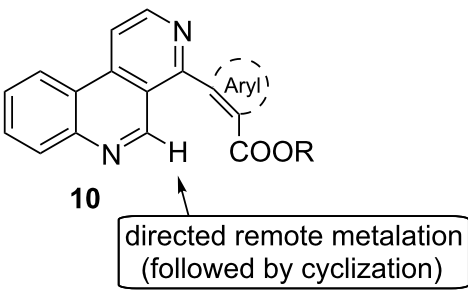

B)

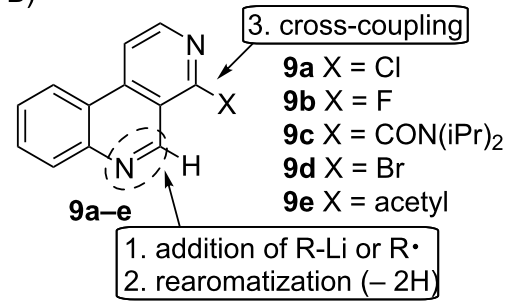

D)

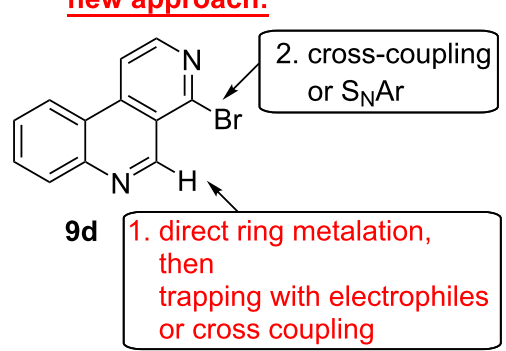

Figure 2: A-C): Published methods for the synthesis of 4,5-disubstituted benzo[c][2,7]naphthyridines; D) New approach.

readily substituted by nucleophiles, we considered bulky, nonnucleophilic amide bases as most promising for the metalation at C-5.

Inspired by reports of Knochel's [19,20] and our group [21-23] on direct metalation of substituted isoquinolines at C-1 and in continuation of our recent work on the synthesis of aromatic oxoaporphine, oxoisoaporphine and pyridoacridine alkaloids $[17,18,21,22]$ using direct ring metalations of heterocycles with the hindered amide base TMPMgCl$\cdot \mathrm{LiCl}$ as crucial step, the Knochel-Hauser base was again the metalation reagent of our choice.

Metalation of 4-bromobenzo[c][2,7]naphthyridine (9d) using 1.1 equivalents $\mathrm{TMPMgCl} \cdot \mathrm{LiCl}$ at $-40{ }^{\circ} \mathrm{C}$, followed by the reaction with various electrophiles gave, in most cases, the expected 5-subsituted products (Scheme 1). Quenching of metalated 9d with aldehydes 11a-d while warming to room temper-<smiles>COc1nc2ccccc2c2ccnc(Br)c12</smiles>

9d

$$
\underset{-40{ }^{\circ} \mathrm{C} \text { to } 25^{\circ} \mathrm{C},}{\frac{11 \mathrm{a}-\mathrm{d}}{20 \mathrm{~min}}}
$$

11a<smiles>O=Cc1ccccc1</smiles>

11b<smiles>O=Cc1cncs1</smiles>

11c<smiles>O=Cc1ccccc1Br</smiles>

11d<smiles>O=Cc1cccnc1Br</smiles><smiles>[R]C(O)c1nc2ccccc2c2ccnc(Br)c12</smiles>

$12 \mathrm{a} R=$ $(50 \%)$<smiles>Ic1ccccc1</smiles>

$12 \mathrm{~b} \mathrm{R}=$ $(61 \%)$

$12 \mathrm{c} R=$ (52\%)<smiles>CCc1ccccc1Br</smiles>

$12 \mathrm{~d} R=$ $(66 \%)$<smiles>CCc1cccnc1Br</smiles> 
ature led to the formation of the expected racemic secondary alcohols 12a-d in moderate to good yields (50-66\%, Scheme 1). Any attempts to improve the yields failed. The use of 2.2 equivalents of base, longer reaction times, higher or lower temperatures did not increase the yields.

In order to explore additional metalations at other positions than C-5 or imaginable halogen dance reactions [24] during the metalation process, we performed a $\mathrm{D}_{2} \mathrm{O}$ quenching experiment after the metalation period. In recovered starting material 9d-D deuterium incorporation (about $60 \%$ calculated from the NMR resonance of 5-H) was detected exclusively at C-5, clearly indicating the regioselectivity of this metalation (Scheme 2). Probably, the metalation rate is even higher than $60 \%$ (compare the $71 \%$ yield for the iodine quenching product 13 ), as $\mathrm{D}_{2} \mathrm{O}$ quenching of metalated arenes obtained with amide bases do not necessarily give complete deuteration. A hydrogen-bonded complex between the metalated species and TMP is postulated to undergo partial $\mathrm{H} / \mathrm{D}$ exchange reactions with $\mathrm{D}_{2} \mathrm{O}$ before quenching takes place [25].

$$
\begin{aligned}
& \text { 1) TMPMgCl.LiCl } \\
& \begin{array}{l}
\text { (1.1 equiv) } \\
\text { THF, }-40{ }^{\circ} \mathrm{C}, 2 \mathrm{D}
\end{array}
\end{aligned}
$$

Scheme 2: Outcome of a $\mathrm{D}_{2} \mathrm{O}$ quenching experiment after metalation of 4 -bromobenzo[c][2,7]naphthyridine $(\mathbf{9 d})$.

The reaction of metalated 9d with diverse electrophiles was tested in further studies. Quenching with iodine gave 5-iodo derivative $\mathbf{1 3}$ in a good yield of $71 \%$. As the group of Knochel could demonstrate [26] that the closely related substrate 1-chloro-4-iodo-2,7-naphthyridine undergoes consecutive cross-coupling reactions, 4-bromo-5 iodobenzo[c][2,7]naphthyridine (13) is regarded as an interesting building block for synthetic chemists. Another interesting building block is ester 14, which was obtained in $37 \%$ yield by quenching 5-metalated 9d with diethyl carbonate. The quenching of $9 \mathbf{d}$ after magnesiation with $N, N$-dimethylformamide did not lead to the expected bromoaldehyde 15 but provided surprisingly the aminoaldehyde 16. Probably, the intermediate aminoalkoxide delivers dimethylamine during aqueous work-up, followed by $\mathrm{S}_{\mathrm{N}} \mathrm{Ar}$ reaction at C-4. Related nucleophilic substitutions have been reported for 4-chlorobenzo[c][2,7]naphthyridine (9a) previously [10]. Alternatively, this $S_{N} A r$ could have taken place under anhydrous conditions directly from the aminoalkoxide. This latter mechanism is in analogy to an intramolecular reaction of a hydrazone derivative proposed by Guillier et al. [12]. Reaction of allyl iodide (17) with metalated 9d after addition of catalytic amounts of $\mathrm{CuCN} \cdot 2 \mathrm{LiCl}$ led to the formation of the 5-allyl compound 18 in 37\% yield. Metalation of 9d using TMPMgCl. $\mathrm{TiCl}$ and subsequent transmetalation with $\mathrm{ZnCl}_{2}$ followed by Negishi cross-coupling reaction in the presence of $\mathrm{Pd}(\mathrm{dba})_{2}$ and $\mathrm{P}(2 \text {-furyl })_{3}$ with aryl iodides $19 \mathbf{a}$ and $\mathbf{1 9 b}$ led to the expected biaryls 20a and 20b in moderate yields (Scheme 3). All these

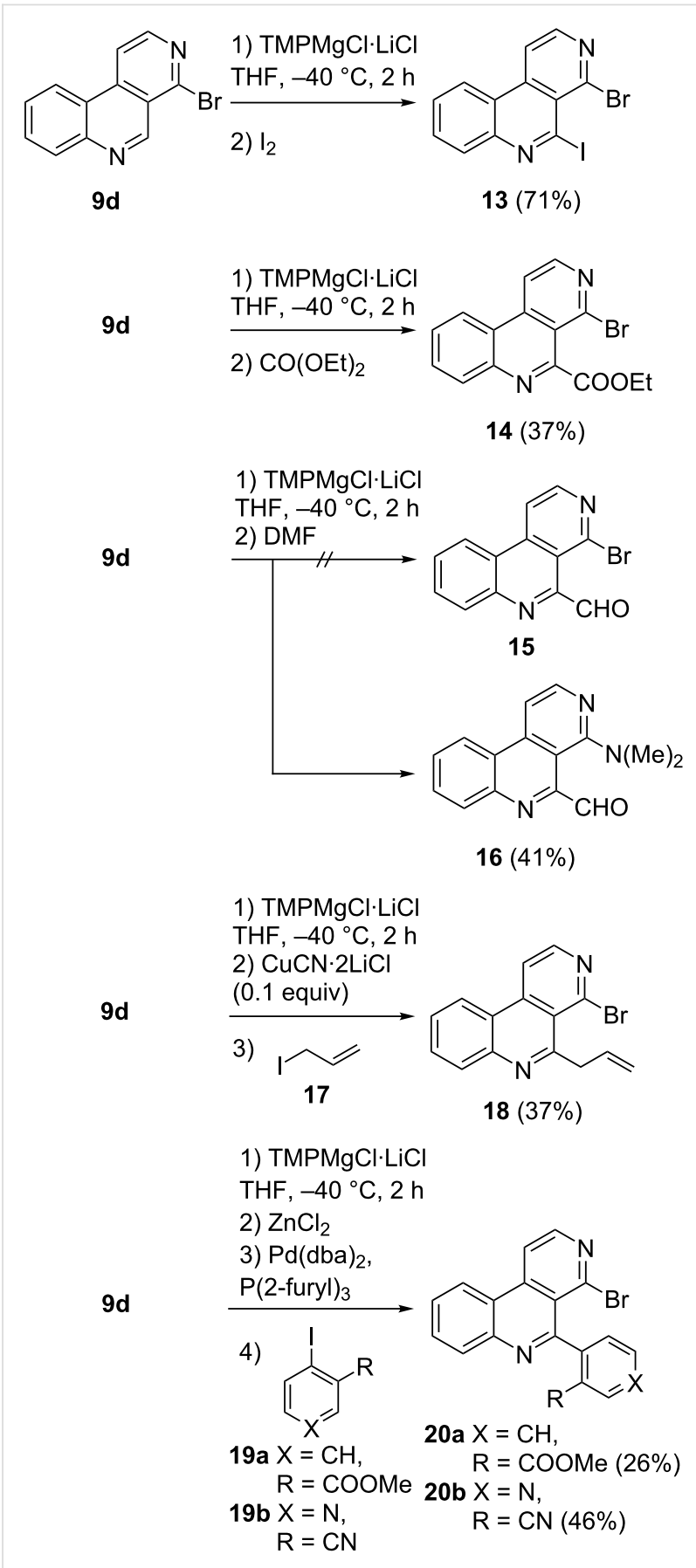

Scheme 3: Synthesis of 5-substituted 4-bromobenzo[c][2,7]naphthyridines via regioselective metalation of $9 \mathrm{~d}$ using $\mathrm{TMPMgCl} \cdot \mathrm{LiCl}$ and quenching with various electrophiles or cross-coupling reactions. 
reactions proceeded without byproducts being observed. In all cases unreacted substrate 9d was recovered in correspondent quantity.

With the 5-(hetero)aryl-substituted 4-bromobenzo[c][2,7]naphthyridines 12a-d in hand we aimed at the synthesis of the respective pyrido[2,3,4- $k l]$ acridines by intramolecular ringclosing steps. Similar $\mathrm{C}-\mathrm{C}$ couplings were performed previously by application of palladium-catalysed cross-coupling reactions, photochemical cyclizations or even in manner of a radical reaction [27-29]. Starting with alcohol 12b, a putative precursor of the alkaloid kuanoniamine A (3), the three described cyclization methodologies were tested starting directly from alcohol 12b as well as from ketone 21, obtained by oxidation of $\mathbf{1 2 b}$. The intramolecular biaryl synthesis via an Hecktype palladium-catalysed reaction according to the method of Harayama [30] (Pd(II)acetate/tri(o-tolyl)phosphine $\left./ \mathrm{K}_{2} \mathrm{CO}_{3}\right)$ did not lead to the expected alkaloid 3 . Also the radical procedure published by Markgraf et al. [31] using AIBN and $\mathrm{Bu}_{3} \mathrm{SnH}$ and a photochemical cyclization protocol we had utilised for the construction of oxoaporphine alkaloids before [21] failed to give kuanoniamine A (3, Scheme 4$)$. In order to explore alternative cyclization protocols, we performed model reactions with 2-bromophenyl analogue 12c. Neither the reaction with diverse Pd catalysts, nor Oliveira's Pd-catalysed intramolecular tandem stannylation/biaryl coupling protocol gave the attempted pentacyclic products [32].

However, having the biaryls 20a and 20b prepared we intended to develop a new approach to pyrido[4,3,2-mn] acridines by an alternative intramolecular cyclization step. To reach that aim, the bromo substituent of the appropriate substrates 20a or 20b should converted into the respective organomagnesium product by bromine-magnesium exchange. In an expected subsequent Parham-type ring-closing reaction [33] the nucleophilic carbon at position 4 should trap the ester (or nitrile) group to lead to a pentacyclic ketone. A similar cyclization reaction was developed by our group some years ago for ester substrates [18], and an analogous cyclization of nitriles was described by Kristensen in ring-closing cascade reactions [34]. The new cyclization method was first tested with ester 20a. Reaction of 20a with 2.2 equiv iPrMgCl$\cdot \mathrm{LiCl}$, which is a very mild reagent for bromine-magnesium exchange reactions in the presence of labile functional groups like esters [35], at $0{ }^{\circ} \mathrm{C}$ led, after aqueous work-up, to the formation of the expected pyridoacridone 22 in $28 \%$ yield (Scheme 5). Although starting material could not be recovered, another product $\mathbf{2 3}$, which is most likely the debrominated, not cyclized analogue of $\mathbf{2 0 a}$, was ob-

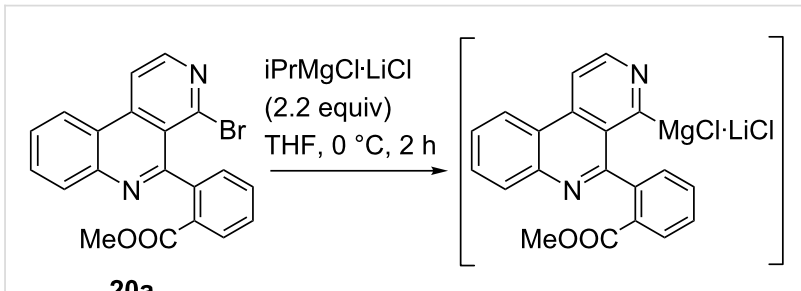

20a
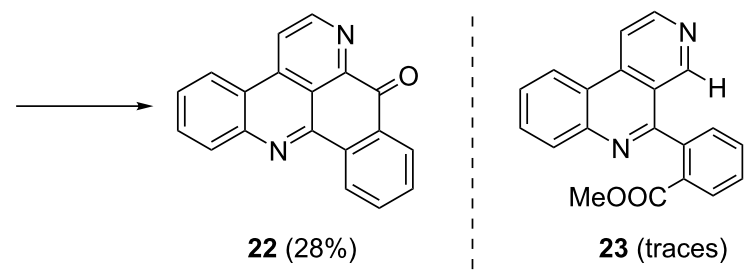

Scheme 5: Synthesis of pyrido[4,3,2-mn]acridone 22 starting from 20 via bromine-magnesium exchange reaction and subsequent intramolecular trapping of the methyl ester.

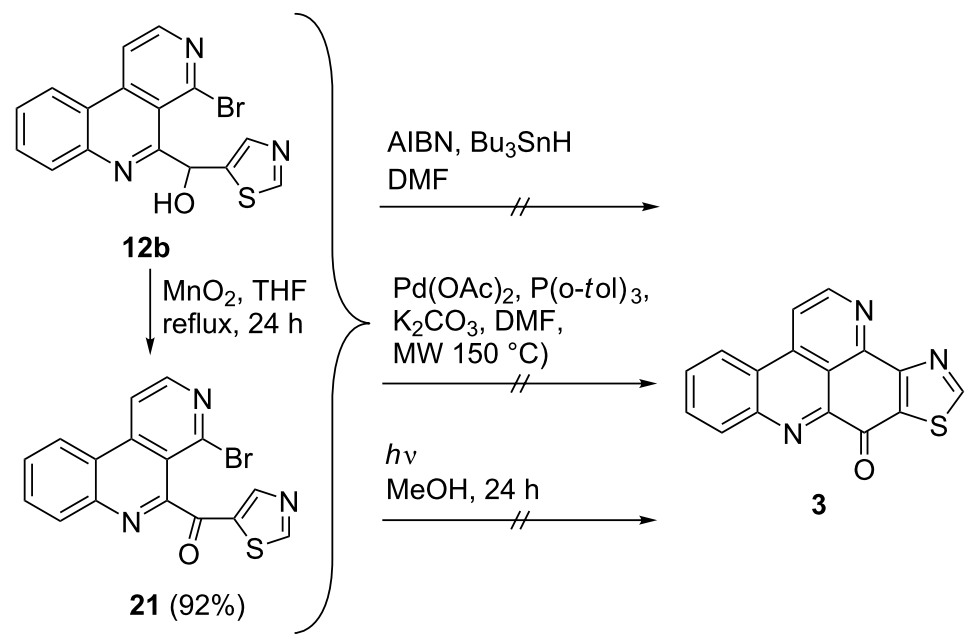


served in traces. The outcome of this experiment shows that the bromine-magnesium exchange reaction was most likely completed, but the intramolecular trapping of the ester group is the limiting factor here. Nevertheless, we could demonstrate that starting from 4-bromobenzo[c][2,7]naphthyridine (9d) a fast and easily affordable new approach to amphimedine-type pyridoacridones and analogues is possible in just two steps.

\section{Conclusion}

In conclusion, we could demonstrate that readily available 4-bromobenzo[c][2,7]naphthyridine (9d) undergoes regioselective direct ring metalation at $\mathrm{C}-5$ with $\mathrm{TMPMgCl} \cdot \mathrm{LiCl}$ at $-40{ }^{\circ} \mathrm{C}$. Quenching with various electrophiles gives a broad range of 5-substituted products, which should be valuable building blocks for the synthesis of heterocyclic natural products and analogues thereof. In combination with a Parham-type cyclization a novel approach to pyrido[4,3,2-mn]acridones could be shown.

\section{Supporting Information}

\section{Supporting Information File 1}

Experimental procedures and characterization of all compounds, NMR spectra.

[https://www.beilstein-journals.org/bjoc/content/ supplementary/1860-5397-15-222-S1.pdf]

\section{Acknowledgements}

The results presented here are part of the Ph.D. theses of Benedikt C. Melzer and Alois Plodek. The authors wish to thank Dr. Marco Keller for significant support in finalizing the manuscript.

\section{ORCID ${ }^{\circledR}$ iDs}

Franz Bracher - https://orcid.org/0000-0003-0009-8629

\section{References}

1. Delfourne, E.; Bastide, J. Med. Res. Rev. 2003, 23, 234-252. doi:10.1002/med.10032

2. Sandjo, L. P.; Kuete, V.; Biavatti, M. W. Beilstein J. Org. Chem. 2015, 11, 1667-1699. doi:10.3762/bjoc.11.183

3. Plodek, A.; Bracher, F. Mar. Drugs 2016, 14, No. 26. doi:10.3390/md14020026

4. Joule, J. A.; Álvarez, M. Eur. J. Org. Chem. 2019, 5043-5072. doi:10.1002/ejoc.201900401

5. Lúcio, A. S. S. C.; Almeida, J. R. G. d. S.; da-Cunha, E. V. L.; Tavares, J. F.; Barbosa Filho, J. M. Alkaloids of the Annonaceae: Occurrence and a Compilation of Their Biological Activities. Chemistry and Biology, The Alkaloids; Academic Press: Waltham, MA, USA, 2015; Vol. 74, pp 233-409. doi:10.1016/bs.alkal.2014.09.002

6. Skyler, D.; Heathcock, C. H. J. Nat. Prod. 2002, 65, 1573-1581. doi:10.1021/np020016y
7. Bracher, F. Arch. Pharm. (Weinheim, Ger.) 1989, 322, 511-512. doi:10.1002/ardp.19893220811

8. Lotter, M.; Bracher, F. Sci. Pharm. 2009, 77, 1-7. doi:10.3797/scipharm.0901-14

9. Godard, A.; Rocca, P.; Guillier, F.; Duvey, G.; Nivoliers, F.; Marsais, F.; Quéguiner, G. Can. J. Chem. 2001, 79, 1754-1761. doi:10.1139/v01-147

10. Duvey, G.; Nivoliers, F.; Rocca, P.; Godard, A.; Marsais, F.; Quéguiner, G. J. Heterocycl. Chem. 2001, 38, 1039-1044. doi:10.1002/jhet.5570380505

11. Guillier, F.; Nivoliers, F.; Godard, A.; Marsais, F.; Queguiner, G.; Siddiqui, M. A.; Snieckus, V. J. Org. Chem. 1995, 60, 292-296. doi:10.1021/jo00107a004

12. Guillier, F.; Nivoliers, F.; Godard, A.; Marsais, F.; Quéguiner, G. J. Heterocycl. Chem. 1999, 36, 1157-1165. doi:10.1002/jhet.5570360508

13. Cochennec, C.; Rocca, P.; Marsais, F.; Godard, A.; Quéguiner, G. J. Chem. Soc., Perkin Trans. 1 1995, 979-984. doi:10.1039/p19950000979

14. Plodek, A.; Raeder, S.; Bracher, F. Tetrahedron 2012, 68, 4693-4700. doi:10.1016/j.tet.2012.04.023

15. Raeder, S.; Bracher, F. Arch. Pharm. (Weinheim, Ger.) 2012, 345 , 822-826. doi:10.1002/ardp.201200019

16. Plodek, A.; Raeder, S.; Bracher, F. Tetrahedron 2013, 69, 9857-9864. doi:10.1016/j.tet.2013.08.085

17. Plodek, A.; König, M.; Bracher, F. Eur. J. Org. Chem. 2015, 1302-1308. doi:10.1002/ejoc.201403502

18. Melzer, B.; Plodek, A.; Bracher, F. J. Org. Chem. 2014, 79, 7239-7242. doi:10.1021/jo501312d

19. Krasovskiy, A.; Krasovskaya, V.; Knochel, P. Angew. Chem., Int. Ed. 2006, 45, 2958-2961. doi:10.1002/anie.200504024

20. Balkenhohl, M.; Knochel, P. SynOpen 2018, 2, 78-95. doi:10.1055/s-0036-1591966

21. Melzer, B.; Bracher, F. Org. Biomol. Chem. 2015, 13, 7664-7672. doi:10.1039/c5ob00926j

22. Melzer, B. C.; Bracher, F. Beilstein J. Org. Chem. 2017, 13, 1564-1571. doi:10.3762/bjoc.13.156

23. Melzer, B. C.; Felber, J. G.; Bracher, F. Beilstein J. Org. Chem. 2018, 14, 130-134. doi:10.3762/bjoc.14.8

24. Schnürch, M.; Spina, M.; Khan, A. F.; Mihovilovic, M. D.; Stanetty, P. Chem. Soc. Rev. 2007, 36, 1046-1057. doi:10.1039/b607701n

25. Weymeels, E.; Awad, H.; Bischoff, L.; Mongin, F.; Trécourt, F.; Quéguiner, G.; Marsais, F. Tetrahedron 2005, 61, 3245-3249. doi:10.1016/j.tet.2004.10.098

26. Greiner, R.; Ziegler, D. S.; Cibu, D.; Jakowetz, A. C.; Auras, F.; Bein, T.; Knochel, P. Org. Lett. 2017, 19, 6384-6387. doi:10.1021/acs.orglett.7b03242

27. Marquise, N.; Harford, P. J.; Chevallier, F.; Roisnel, T.; Wheatley, A. E. H.; Gros, P. C.; Mongin, F. Tetrahedron Lett. 2013, 54 , 3154-3157. doi:10.1016/j.tetlet.2013.04.020

28. Chuang, T.-H.; Li, C.-F.; Lee, H.-Z.; Wen, Y.-C. J. Org. Chem. 2013, 78, 4974-4984. doi:10.1021/j0400645g

29. Dobbs, A. P.; Jones, K.; Veal, K. T. Tetrahedron Lett. 1997, 38 , 5379-5382. doi:10.1016/s0040-4039(97)01177-5

30. Harayama, T.; Akiyama, T.; Akamatsu, H.; Kawano, K.; Abe, H.; Takeuchi, Y. Synthesis 2001, 444-450. doi:10.1055/s-2001-11424

31. Markgraf, J. H.; Dowst, A. A.; Hensley, L. A.; Jakobsche, C. E.; Kaltner, C. J.; Webb, P. J.; Zimmerman, P. W. Tetrahedron 2005, 61, 9102-9110. doi:10.1016/j.tet.2005.07.034 
32. Olivera, R.; SanMartin, R.; Tellitu, I.; Domınguez, E. Tetrahedron 2002, 58, 3021-3037. doi:10.1016/s0040-4020(02)00194-1

33. Parham, W. E.; Bradsher, C. K. Acc. Chem. Res. 1982, 15, 300-305. doi:10.1021/ar00082a001

34. Kristensen, J. L.; Vedsø, P.; Begtrup, M. J. Org. Chem. 2003, 68, 4091-4092. doi:10.1021/jo0300340

35. Krasovskiy, A.; Knochel, P. Angew. Chem., Int. Ed. 2004, 43, 3333-3336. doi:10.1002/anie.200454084

\section{License and Terms}

This is an Open Access article under the terms of the Creative Commons Attribution License

(http://creativecommons.org/licenses/by/4.0). Please note that the reuse, redistribution and reproduction in particular requires that the authors and source are credited.

The license is subject to the Beilstein Journal of Organic Chemistry terms and conditions:

(https://www.beilstein-journals.org/bjoc)

The definitive version of this article is the electronic one which can be found at: doi:10.3762/bjoc. 15.222 